\title{
Cannabidiol (CBD) Prevents Palmitic Acid-Induced Drop in Mitochondrial Membrane Potential
}

\author{
R. Gallily' ${ }^{1}$ Z. Yekhtin'1, M. Tarshis ${ }^{2}$, R. Vogt Sionov ${ }^{1}$ \\ ${ }^{1}$ The Lautenberg Center for General and Tumor Immunology, The Hadassah Medical School, The Hebrew University of \\ Jerusalem, Jerusalem, Israel \\ ${ }^{2}$ Inter-Department Unit, The Hadassah Medical School, The Hebrew University of Jerusalem, Jerusalem, Israel \\ Email: ruthg@ekmd.huji.ac.il
}

How to cite this paper: Gallily, R., Yekhtin, Z., Tarshis, M. and Sionov, R.V. (2019) Cannabidiol (CBD) Prevents Palmitic Acid-Induced Drop in Mitochondrial Membrane Potential. Pharmacology \& Pharmacy, 10, 387-395.

https://doi.org/10.4236/pp.2019.109031

Received: July 25, 2019

Accepted: September 8, 2019

Published: September 11, 2019

Copyright (c) 2019 by author(s) and Scientific Research Publishing Inc. This work is licensed under the Creative Commons Attribution International License (CC BY 4.0).

http://creativecommons.org/licenses/by/4.0/

\begin{abstract}
Exposure of macrophages and microglia cells to the saturated palmitic acid (PA) leads to reduction in the mitochondrial membrane potential $\left(\Delta \Psi_{\mathrm{m}}\right)$, shrinkage of the cells and apoptosis. Here we show that the Cannabis component Cannabidiol (CBD) rescues both macrophages and microglia cells from the detrimental effects of $\mathrm{PA}$. CBD prevents the shrinkage in cell size and the reduction in $\Delta \Psi_{\mathrm{m}}$ caused by PA. The protective effect of CBD on the macrophage mitochondria is important for sustaining the macrophage population even under the immunosuppressed conditions caused by this drug. To a similar extent, the antagonistic effect of $\mathrm{CBD}$ on PA-mediated microglia cytotoxicity is important for its role in neuroprotection.
\end{abstract}

\section{Keywords}

CBD, Mitochondrial Membrane Potential, Macrophages, Microglia, Palmitic Acid

\section{Introduction}

Cannabidiol (CBD) is known to exert strong anti-inflammatory and anti-nociceptive properties [1]-[6], besides its well-known anti-microbial activities [7]. In addition, CBD has been shown to be neuroprotective and possess anti-oxidative activities [8]. These promiscuous properties have made CBD a broad-spectrum attractive drug for the treatment of a wide range of diseases such as autoimmune diseases, rheumatoid arthritis, multiple sclerosis and diabetes, and for the alleviation of cancer-associated and other disease-associated pain [6] [9]. In addition, 
CBD has been shown to exert anti-epileptic, anxiolytic and anti-psychotic activities [8].

$\Delta^{9}$-tetrahydrocannabinol (THC), $\mathrm{CBD}$ and their derivatives have previously been shown to modulate several macrophage functions such as inhibition of phagocytosis and chemotaxis as well as repression of $\operatorname{TNF} \alpha$, reactive oxygen species (ROS) and nitric oxide (NO.) production [4] [6] [10] [11] [12] [13]. CBD also alters microglial gene expression in response to lipopolysaccharides, with a prominent elevation of $\mathrm{Nrf2}$-regulated genes involved in oxidant defense and redox signaling [14].

Palmitic acid (PA) leads to apoptosis of macrophages in a CD36-dependent manner [15] [16]. It causes apoptosis through generation of ROS by the NADPH oxidase subunit NOX2 [15]. PA also activates microglia cells, leading to their increased secretion of pro-inflammatory cytokines, ROS and NO. production, which ultimately trigger bystanding neuronal death [17].

Here we show that $\mathrm{CBD}$ rescues macrophages and microglia cells from the cytotoxic effects of PA. Of particular interest is the antagonistic effect of CBD on the PA-mediated drop in mitochondrial membrane potential.

\section{Material and Methods}

\subsection{Reagents}

Purified Cannabidiol (CBD; THC Pharm. GmbH, Frankfurt, Germany) was dissolved in ethanol:Cremophor:saline at a 1:1:18 ratio. Palmitic acid (PA; Sigma) was dissolved in ethanol, and then diluted in DMEM containing $1 \%$ heat-inactivated fetal calf serum (FCS) and $1 \%$ bovine serum albumin. Red MitoTracker $\mathrm{CM}-\mathrm{H}_{2} \mathrm{XRos}$ (Molecular Probes, Life Technologies) was dissolved in DMSO.

\subsection{Cell Culture}

RAW 264.7 macrophage cell line and BV-2 microglial cell lines were grown in DMEM supplemented with $10 \%$ heat-inactivated FCS, and incubated at $37^{\circ} \mathrm{C}$ in a humidified atmosphere containing $5 \% \mathrm{CO}_{2}$.

\subsection{Treatments}

RAW 264.7 or BV-2 cells were incubated with $75-150 \mu \mathrm{M}$ PA in the absence or presence of $1-5 \mu \mathrm{g} / \mathrm{ml} \mathrm{CBD}$ for $24 \mathrm{hrs}$. 30 minutes before the end of incubation, the cells were exposed to $10 \mu \mathrm{M}$ Red MitoTracker. Immediately thereafter, the cultures were inspected by confocal microscopy (Nikon A1 HD25). The relative red intensity was calculated by ImageJ measurements divided by number of cells. Control cells received the respective vehicles.

\subsection{Statistics}

The results are presented as average \pm standard error. $p$-values were calculated from two-tail Student's t-tests. A p-value equal or below 0.05 was considered sta- 
tistically significant.

\section{Results}

\subsection{Cannabidiol (CBD) Prevents Palmitic Acid (PA)-Induced Drop in Mitochondrial Membrane Potential in Macrophages}

Palmitic acid (PA) has previously been shown to induce apoptosis of macrophages [15] [16]. Here we show that a 24 hrs incubation with palmitic acid leads to strong reduction in mitochondrial membrane potential (Figure 1; compare D-F with A-C) with concomitant shrinkage and rounding up of cells with occasional appearance of blebbing cells indicative for apoptosis (Figure 2; compare $\mathrm{D}-\mathrm{F}$ with A-C). ImageJ analysis of red fluorescence intensity/cell shows an $80 \% \pm$ $4 \%$ reduction in MitoTracker staining of PA-treated macrophages (Figure 3(A); $p=0.02)$. However, when the macrophages were simultaneously treated with CBD, the PA-induced drop in $\Delta \Psi_{\mathrm{m}}$ was significantly prevented (Figure 1; compare G-I with D-E; and Figure $3(\mathrm{~A})$ with a $\mathrm{p}=0.002)$. ImageJ analysis
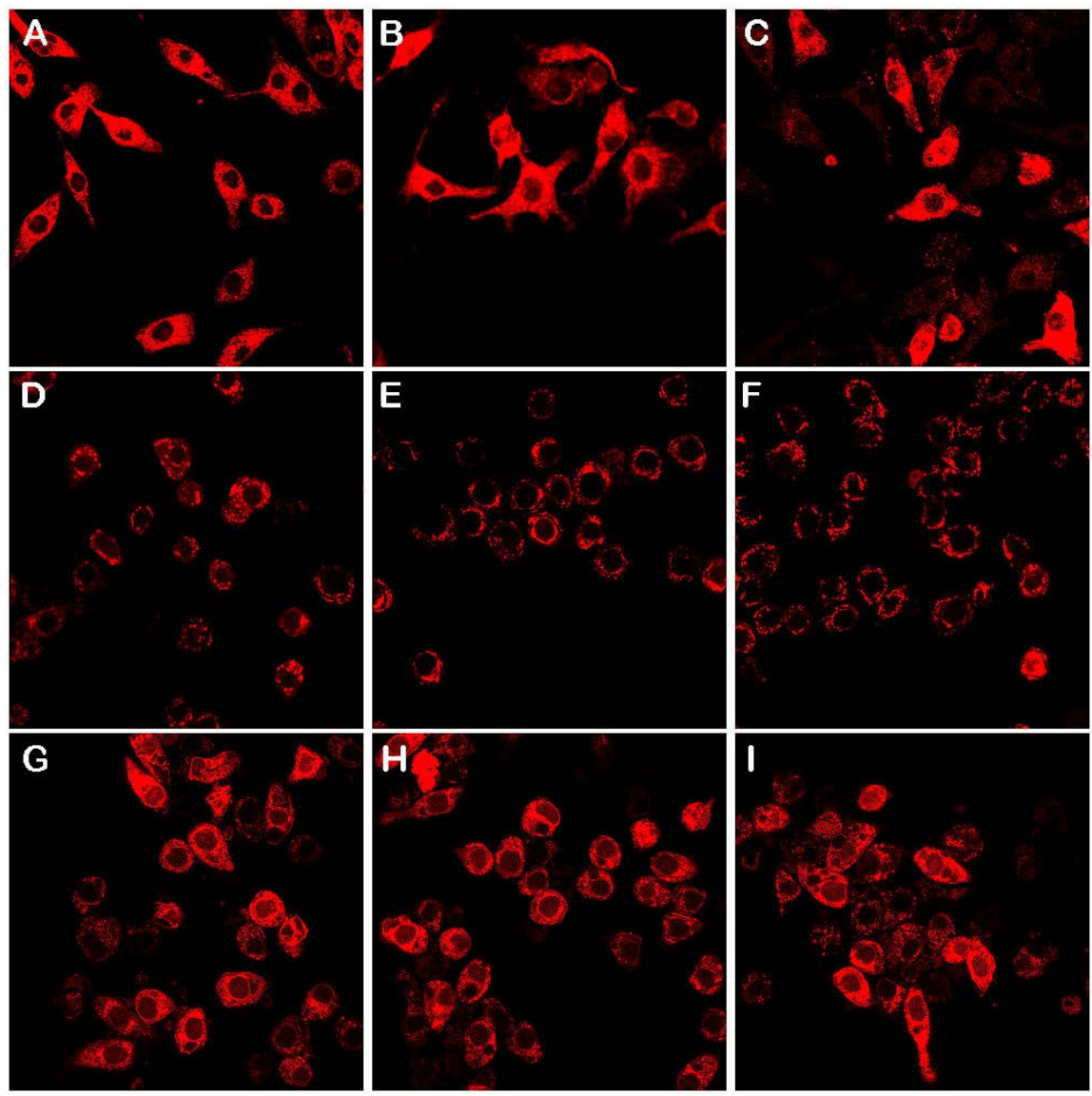

Figure 1. CBD protects RAW 264.7 macrophages from PA-induced drop in mitochondrial membrane potential. RAW 264.7 macrophages were incubated in the absence or presence of $75 \mu \mathrm{M}$ PA alone or together with $5 \mu \mathrm{g} / \mathrm{ml}$ CBD for $24 \mathrm{hrs}$. Red MitoTracker was added to a final concentration of $10 \mu \mathrm{M} 30 \mathrm{~min}$ before the end of incubation. (A) (C) Macrophages incubated with vehicle only; (D) - (F) Macrophages incubated with 75 $\mu \mathrm{M}$ PA; (G) - (I) Macrophages incubated with $75 \mu \mathrm{M}$ PA and $5 \mu \mathrm{g} / \mathrm{ml} \mathrm{CBD.}$ 

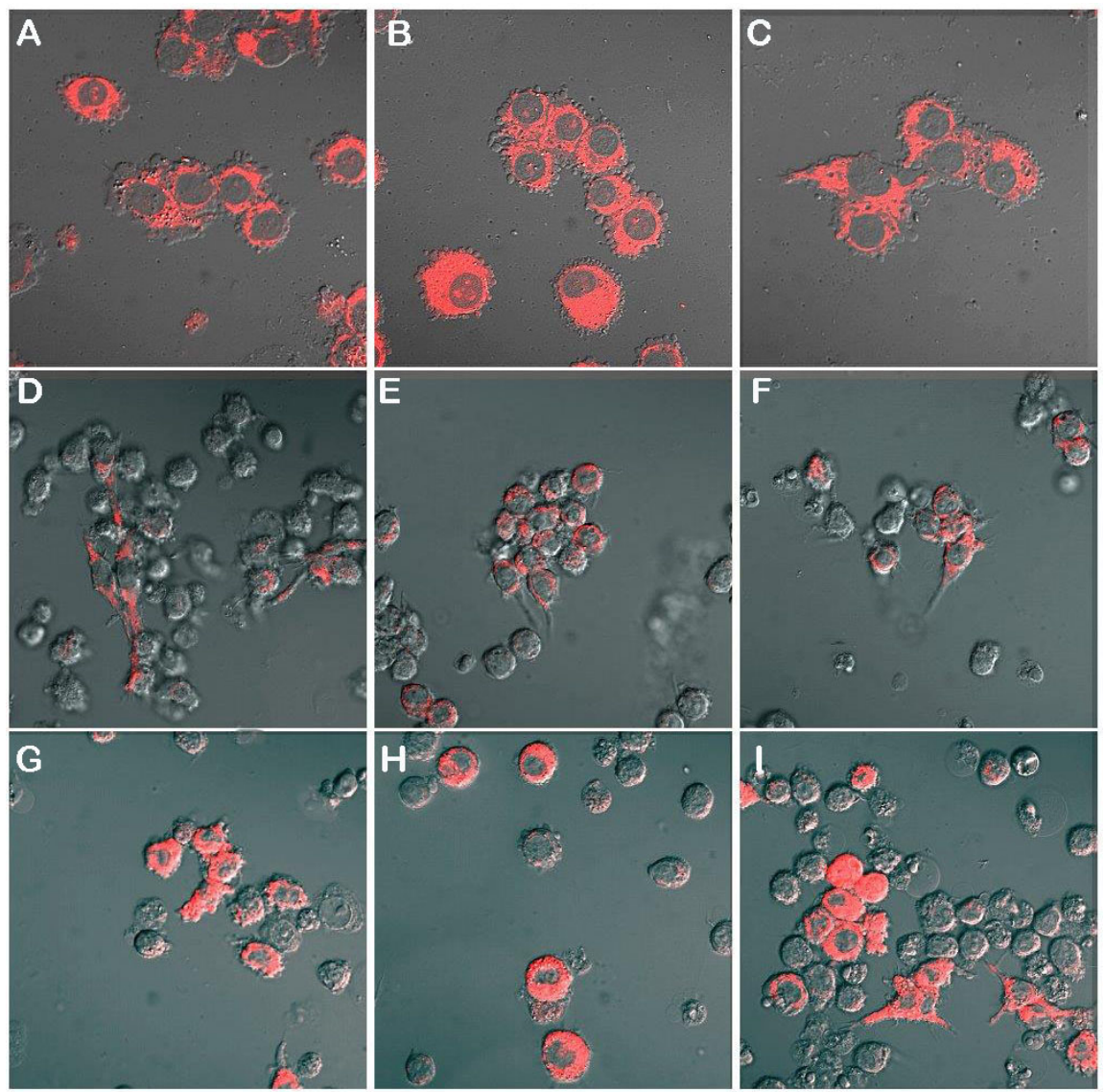

Figure 2. CBD protects RAW 264.7 macrophages from PA-mediated cytotoxicity. RAW 264.7 macrophages were incubated in the absence or presence of $150 \mu \mathrm{M}$ PA alone or together with $5 \mu \mathrm{g} / \mathrm{ml}$ CBD for $24 \mathrm{hrs}$. Red MitoTracker was added to a final concentration of $10 \mu \mathrm{M} 30 \mathrm{~min}$ before the end of incubation. (A) - (C) Macrophages incubated with vehicle only; (D) - (F) Macrophages incubated with $150 \mu \mathrm{M}$ PA; (G) - (I) Macrophages incubated with $150 \mu \mathrm{M}$ PA and $5 \mu \mathrm{g} / \mathrm{ml} \mathrm{CBD}$.

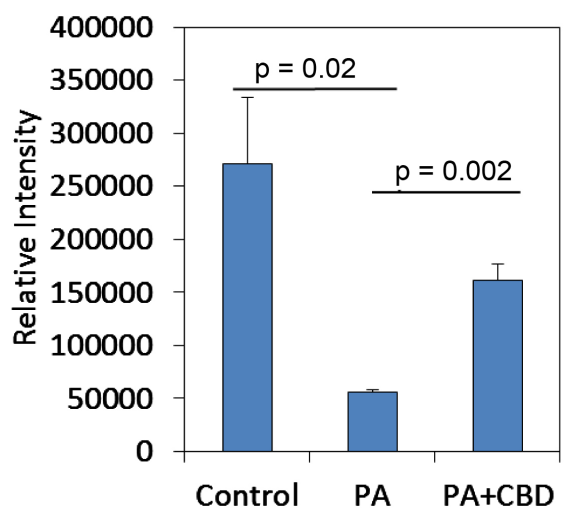

(A)

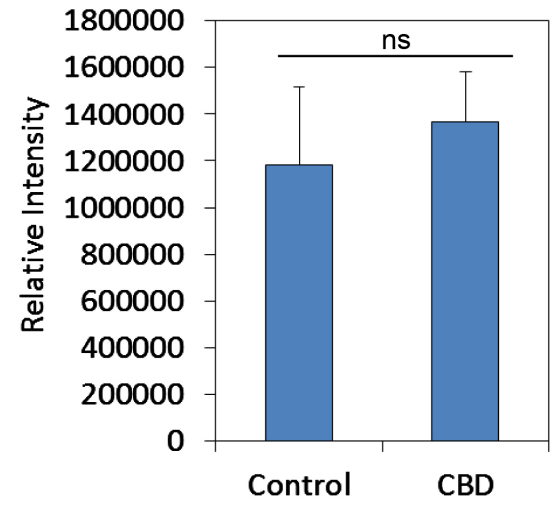

(B)

Figure 3. The relative red fluorescence intensity of macrophages treated with PA and/or CBD. (A) The relative red fluorescence of Red MitoTracker staining of macrophages treated with vehicle (Control), $75 \mu \mathrm{M}$ PA alone or $75 \mu \mathrm{M}$ PA together with $5 \mu \mathrm{g} / \mathrm{ml} \mathrm{CBD}$ for $24 \mathrm{hrs}$; (B) The relative red fluorescence of Red MitoTracker staining of macrophages treated with vehicle (Control) or $5 \mu \mathrm{g} / \mathrm{ml} \mathrm{CBD}$ for $24 \mathrm{hrs}$. 
showed that macrophages co-treated with $\mathrm{CBD}$ and PA had only a $40 \% \pm 5 \%$ reduction in MitoTracker staining in comparison to control macrophages (Figure 1; compare G-H with A-C). Compared to PA-treated macrophages, there was a 3-fold increase in MitoTracker staining in the presence of CBD. CBD also prevented the rounding up of macrophages (Figure 1 and Figure 2), suggesting for a pro-survival effect. The CBD protection was more profound when the macrophages were treated with $75 \mu \mathrm{M}$ PA (Figure 1), than when treated with $150 \mu \mathrm{M}$ PA (Figure 2). Macrophages treated with CBD alone showed similar MitoTracker staining as control cells (Figure 3(B) and Figure 4).

\subsection{CBD Prevents PA-Mediated Cytotoxicity of Microglia Cells}

Palmitic acid has previously been shown to reduce the viability of microglia cells [18]. This is also demonstrated here by exposing BV-2 microglia cells to $75 \mu \mathrm{M}$ $\mathrm{PA}$ for $24 \mathrm{hrs}$ resulting in a $55 \% \pm 5 \%$ reduction in cell viability (Figure 5 compare D-F to A-C; and Figure 6). Simultaneous exposure of microglia cells to both $75 \mu \mathrm{M}$ PA and $5 \mu \mathrm{g} / \mathrm{ml}$ CBD prevented the cytotoxic effect of PA (Figure 5 compare G-I with D-F; and Figure 6), suggesting for a protective role for CBD.

\section{Discussion}

Cannabidiol (CBD) has repeatedly been shown to exert immunosuppressive effects in vivo [1] [2] [3] [4]. In vitro, CBD has been shown to suppress several macrophage functions such as phagocytosis, and the production of TNF $\alpha$, ROS and NO. in response to stimulus [4] [6] [10] [11] [12] [13]. Here we have shown that $\mathrm{CBD}$ antagonizes the cytotoxic effects of PA on both macrophages and microglia cells. CBD prevented the drop in mitochondrial membrane potential
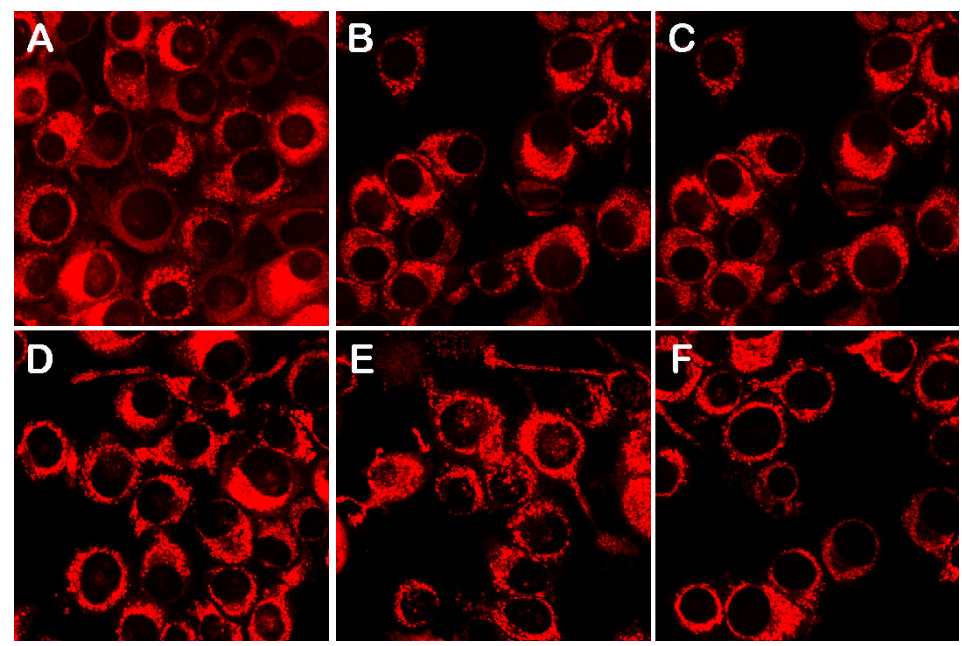

Figure 4. Red Mitotracker staining of control and CBD-treated macrophages. RAW 264.7 macrophages were incubated in the absence or presence of $5 \mu \mathrm{g} / \mathrm{ml} \mathrm{CBD}$ for $24 \mathrm{hrs}$. Red MitoTracker was added to a final concentration of $10 \mu \mathrm{M} 30 \mathrm{~min}$ before the end of incubation. (A) - (C) Macrophages incubated with vehicle only; (D) - (F) Macrophages incubated with $5 \mu \mathrm{g} / \mathrm{ml} \mathrm{CBD}$. 

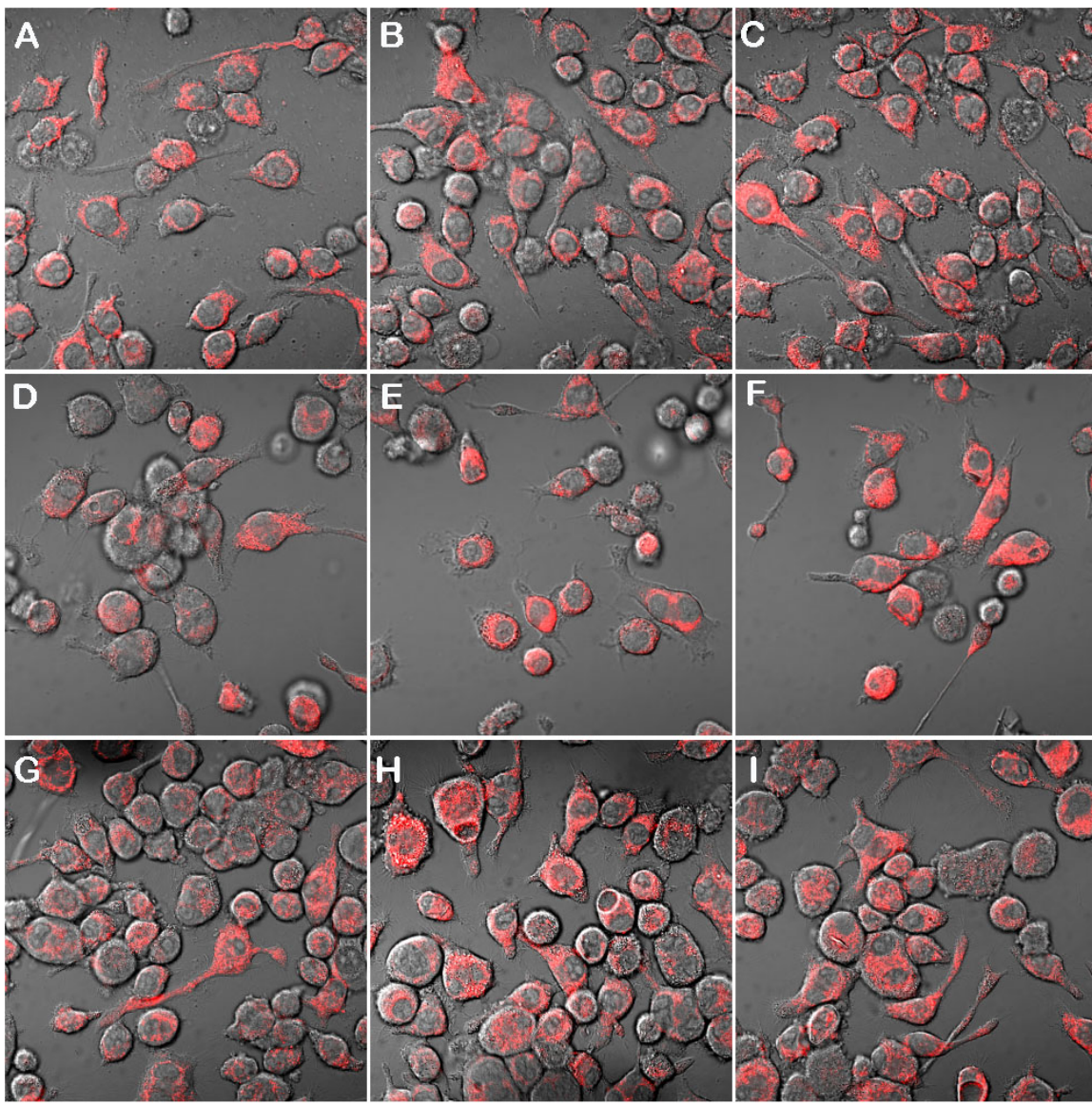

Figure 5. CBD antagonizes the cytotoxic effects of PA on microglia cells. BV-2 microglia cells were incubated in the absence or presence of $75 \mu \mathrm{M}$ PA alone or together with 5 $\mu \mathrm{g} / \mathrm{ml} \mathrm{CBD}$ for $24 \mathrm{hrs}$. Red MitoTracker was added to a final concentration of $10 \mu \mathrm{M} 30$ min before the end of incubation. (A) - (C) BV-2 microglia cells incubated with vehicle only; (D) - (F) BV-2 microglia cells incubated with $75 \mu \mathrm{M}$ PA; (G) - (I) BV-2 microglia cells incubated with $75 \mu \mathrm{M}$ PA and $5 \mu \mathrm{g} / \mathrm{ml} \mathrm{CBD}$.

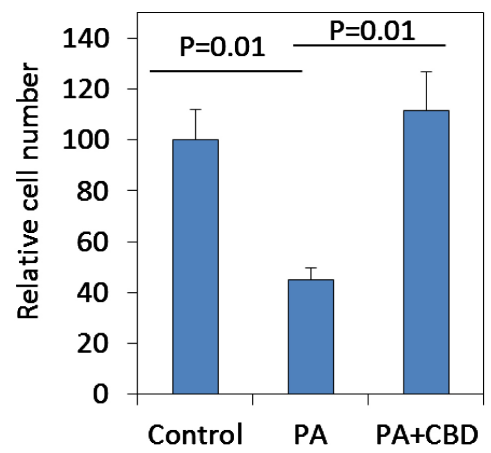

Figure 6. The relative number of microglia cells treated with PA alone or together with CBD. BV-2 microglia cells were incubated in the absence or presence of $75 \mu \mathrm{M}$ PA alone or together with $5 \mu \mathrm{g} / \mathrm{ml} \mathrm{CBD}$ for $24 \mathrm{hrs}$. The relative cell number is presented in comparison to vehicle-treated cells (Control).

caused by PA. A recent study has observed a similar protection of hepatocytes from PA-induced apoptosis by CBD [19]. These authors observed that PA re- 
duced the mitochondrial membrane potential and increased the mitochondrial reactive oxygen species production in hepatocytes, both effects antagonized by $\mathrm{CBD}$ [19]. Also the neuroprotective activity of CBD has been related to its effects on mitochondria [20], where CBD under pathophysiological conditions prevented apoptosis via restoration of $\mathrm{Ca}^{2+}$ homeostasis. $\mathrm{CBD}$ interacts with $\mathrm{Ca}^{2+}$ TRP channels [6], which might account for this effect. The pro-survival effect of $\mathrm{CBD}$ on macrophages observed in the present study is intriguing in light of its ability to suppress various macrophage functions. This characteristic of CBD is important for sustaining the macrophage population even under immunosuppressed conditions. Similarly, the pro-survival effect of CBD on microglia is important for neuroprotection. In both macrophages and microglia cells, there is a correlation between the documented reduction in ROS and NO. production caused by $\mathrm{CBD}$ and the preservation of mitochondrial function described in the present study. It is thus likely that the anti-oxidant properties of CBD contribute to the survival of both macrophages and microglia cells.

\section{Conflicts of Interest}

The authors declare no conflicts of interest.

\section{References}

[1] Gallily, R. and Yekhtin, Z. (2019) Avidekel Cannabis Extracts and Cannabidiol Are as Efficient as Copaxone in Suppressing EAE in SJL/J Mice. Inflammopharmacolo$g y, 27$, 167-173. https://doi.org/10.1007/s10787-018-0536-3

[2] Weiss, L., Zeira, M., Reich, S., Slavin, S., Raz, I., Mechoulam, R. and Gallily, R. (2008) Cannabidiol Arrests Onset of Autoimmune Diabetes in NOD Mice. Neuropharmacology, 54, 244-249. https://doi.org/10.1016/j.neuropharm.2007.06.029

[3] Gallily, R., Yekhtin, Z. and Hanuš, L.O. (2015) Overcoming the Bell-Shaped DoseResponse of Cannabidiol by Using Cannabis Extract Enriched in Cannabidiol. Pharmacology \& Pharmacy, 6, 75-85. https://doi.org/10.4236/pp.2015.62010

[4] Malfait, A.M., Gallily, R., Sumariwalla, P.F., Malik, A.S., Andreakos, E., Mechoulam, R. and Feldmann, M. (2000) The Nonpsychoactive Cannabis Constituent Cannabidiol Is an Oral Anti-Arthritic Therapeutic in Murine Collagen-Induced Arthritis. Proceedings of the National Academy of Sciences of the United States of America, 97, 9561-9566. https://doi.org/10.1073/pnas.160105897

[5] Watkins, A.R. (2019) Cannabinoid Interactions with Ion Channels and Receptors. Channels (Austin), 13, 162-167. https://doi.org/10.1080/19336950.2019.1615824

[6] McPartland, J.M., Duncan, M., Di Marzo, V. and Pertwee, R.G. (2015) Are Cannabidiol and $D^{9}$-Tetrahydrocannabivarin Negative Modulators of the Endocannabinoid System? A Systematic Review. British Journal of Pharmacology, 172, 737-753. https://doi.org/10.1111/bph.12944

[7] Appendino, G., Gibbons, S., Giana, A., Pagani, A., Grassi, G., Stavri, M., Smith, E. and Rahman, M.M. (2008) Antibacterial Cannabinoids from Cannabis sativa: A Structure-Activity Study. Journal of Natural Products, 71, 1427-1430. https://doi.org/10.1021/np8002673

[8] Crippa, J.A., Guimaraes, F.S., Campos, A.C. and Zuardi, A.W. (2018) Translational Investigation of the Therapeutic Potential of Cannabidiol (CBD): Toward a New 
Age. Frontiers in Immunology, 9, 2009. https://doi.org/10.3389/fimmu.2018.02009

[9] Pisanti, S., Malfitano, A.M., Ciaglia, E., Lamberti, A., Ranieri, R., Cuomo, G., Abate, M., Faggiana, G., Proto, M.C., Fiore, D., et al. (2017) Cannabidiol: State of the Art and New Challenges for Therapeutic Applications. Pharmacology \& Therapeutics, 175, 133-150. https://doi.org/10.1016/j.pharmthera.2017.02.041

[10] Sacerdote, P., Martucci, C., Vaccani, A., Bariselli, F., Panerai, A.E., Colombo, A., Parolaro, D. and Massi, P. (2005) The Nonpsychoactive Component of Marijuana Cannabidiol Modulates Chemotaxis and IL-10 and IL-12 Production of Murine Macrophages Both in Vivo and in Vitro. Journal of Neuroimmunology, 159, 97-105. https://doi.org/10.1016/j.jneuroim.2004.10.003

[11] Haj, C.G., Sumariwalla, P.F., Hanus, L., Kogan, N.M., Yektin, Z., Mechoulam, R., Feldmann, M. and Gallily, R. (2015) HU-444, a Novel, Potent Anti-Inflammatory, Nonpsychotropic Cannabinoid. Journal of Pharmacology and Experimental Therapeutics, 355, 66-75. https://doi.org/10.1124/jpet.115.226100

[12] Ben-Shabat, S., Hanus, L.O., Katzavian, G. and Gallily, R. (2006) New Cannabidiol Derivatives: Synthesis, Binding to Cannabinoid Receptor, and Evaluation of Their Antiinflammatory Activity. Journal of Medicinal Chemistry, 49, 1113-1117. https://doi.org/10.1021/jm050709m

[13] Steffens, S., Veillard, N.R., Arnaud, C., Pelli, G., Burger, F., Staub, C., Karsak, M., Zimmer, A., Frossard, J.L. and Mach, F. (2005) Low Dose Oral Cannabinoid Therapy Reduces Progression of Atherosclerosis in Mice. Nature, 434, 782-786. https://doi.org/10.1038/nature03389

[14] Juknat, A., Gao, F., Coppola, G., Vogel, Z. and Kozela, E. (2019) miRNA Expression Profiles and Molecular Networks in Resting and LPS-Activated BV-2 Microglia-Effect of Cannabinoids. PLoS ONE, 14, e0212039.

https://doi.org/10.1371/journal.pone.0212039

[15] Seimon, T.A., Nadolski, M.J., Liao, X., Magallon, J., Nguyen, M., Feric, N.T., Koschinsky, M.L., Harkewicz, R., Witztum, J.L., Tsimikas, S., et al. (2010) Atherogenic Lipids and Lipoproteins Trigger CD36-TLR2-Dependent Apoptosis in Macrophages Undergoing Endoplasmic Reticulum Stress. Cell Metabolism, 12, 467-482. https://doi.org/10.1016/j.cmet.2010.09.010

[16] Kim, D.H., Cho, Y.M., Lee, K.H., Jeong, S.W. and Kwon, O.J. (2017) Oleate Protects Macrophages from Palmitate-Induced Apoptosis through the Downregulation of CD36 Expression. Biochemical and Biophysical Research Communications, 488, 477-482. https://doi.org/10.1016/j.bbrc.2017.05.066

[17] Wang, Z., Liu, D., Wang, F., Liu, S., Zhao, S., Ling, E.A. and Hao, A. (2012) Saturated Fatty Acids Activate Microglia via Toll-Like Receptor 4/NF-kappaB Signalling. British Journal of Nutrition, 107, 229-241. https://doi.org/10.1017/S0007114511002868

[18] Hidalgo-Lanussa, O., Avila-Rodriguez, M., Baez-Jurado, E., Zamudio, J., Echeverria, V., Garcia-Segura, L.M. and Barreto, G.E. (2018) Tibolone Reduces Oxidative Damage and Inflammation in Microglia Stimulated with Palmitic Acid through Mechanisms Involving Estrogen Receptor Beta. Molecular Neurobiology, 55, 54625477. https://doi.org/10.1007/s12035-017-0777-y

[19] Chen, R., Gao, X., Zhang, L., Zhao, W., Zeng, L., Zhu, Y. and Fu, Z. (2018) Cannabidiol Attenuates Palmitic Acid-Induced Injury in Cultured Hepatocytes through Promoting Autophagic Flux. International Journal of Clinical and Experimental Medical Sciences, 4, 51-56. https://doi.org/10.11648/j.ijcems.20180403.15 
[20] Ryan, D., Drysdale, A.J., Lafourcade, C., Pertwee, R.G. and Platt, B. (2009) Cannabidiol Targets Mitochondria to Regulate Intracellular $\mathrm{Ca}^{2+}$ Levels. Journal of Neuroscience, 29, 2053-2063. https://doi.org/10.1523/JNEUROSCI.4212-08.2009 